\title{
No man is an island: Psychological underpinnings of prosociality in the midst of the COVID-19 outbreak ${ }^{\text {it }}$
}

\author{
Emanuele Politi $^{\mathrm{a}, \mathrm{b}, *}$, Jasper Van Assche ${ }^{\mathrm{a}, \mathrm{c}}$, Gian Vittorio Caprara ${ }^{\mathrm{d}}$, Karen Phalet $^{\mathrm{a}}$ \\ ${ }^{\text {a }}$ KU Leuven, Belgium \\ ${ }^{\mathrm{b}}$ University of Lausanne, Switzerland \\ c Ghent University, Belgium \\ ${ }^{\mathrm{d}}$ University of Roma La Sapienza, Italy
}

\section{A R T I C L E I N F O}

\section{Keywords:}

COVID-19

Prosociality

Basic individual values

RWA

SDO

Core political values

Bonding

Bridging

\begin{abstract}
A B S T R A C T
In response to the COVID-19 outbreak, sustainable forms of collective resilience help societies coping cohesively with unprecedented challenges. In our empirical contribution, we framed collective resilience and cohesion in terms of prosociality. A study carried out in the midst of the COVID-19 outbreak in the UK $(N=399)$ articulated basic individual values, ideological orientations (i.e., authoritarianism and social dominance orientation), and core political values in a comprehensive framework to predict bonding and bridging forms of prosocial intentions, and prosocial behaviors directed towards vulnerable groups. According to our findings, people whose worldview incorporates collective and collaborative principles cared more about others' welfare. Jointly, selftranscendence, equality, and accepting immigrants predicted more prosociality, whereas social dominance orientation predicted less prosociality. Over and beyond all other predictors, self-transcendence uniquely predicted prosocial intentions and behaviors alike. To conclude, we suggest interventions to promote and sustain prosociality among people motivated by a larger array of life goals and worldviews.
\end{abstract}

\section{Introduction}

Apart from the immediate threat to public health, the COVID-19 outbreak fueled societal stressors, further exacerbated by social distancing regulations to restrain the virus. Even after confinement will be alleviated in a number of countries, long-term effects on individuals and communities are still to be fully understood. In response to the formidable challenge humanity is facing, prosociality may be the best antibody to cure infected societies. Not only do solidarity initiatives equip individuals with material resources to bounce back from stressful events, they also hold the social fabric together and preserve social cohesion (Drury, 2012; Solnit, 2009).

Our contribution aims precisely at pinpointing the psychological underpinnings of a large array of prosocial activities. Prosociality can be broadly understood as a "set of voluntary actions one may adopt to help, take care of, assist, or comfort others" (Caprara, Steca, Zelli, \& Capanna, 2005, p. 77). Importantly, prosociality encompasses a large array of "others", not only binding people within existing social networks, but also connecting people across social cleavages (Batson, 1991; Graziano, Habashi, Sheese, \& Tobin, 2007). Borrowing the expression from social capital literature (Patulny \& Lind Haase Svendsen, 2007), in our research we distinguished between a narrow "bonding" type of prosociality, related to face-to-face networks within one's own community, and a "bridging" variant of prosociality, directed towards vulnerable populations across group boundaries.

People are generally more inclined to help and support those who are psychologically and physically close, such as relatives, neighbors, and fellow nationals, compared to those who are psychologically and physically distant, such as acquaintances, strangers, and foreigners (Andrighetto, Vezzali, Bergamini, Nadi, \& Giovannini, 2016; Baron \& Szymanska, 2011). What is more, as opposed to broader prosocial attitudes or intentions, specific prosocial behaviors may be more loosely connected to personal values and world views. As people strive to enact their intentions, indeed, people may face various social reality

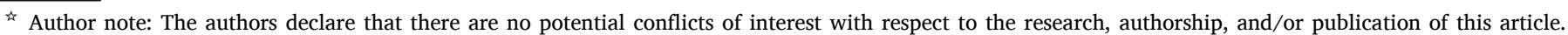
Dataset wording of all relevant measures and additional analyses can be found online at https://doi.org/10.1016/j.paid.2020.110534.

* Corresponding author at: Center for Social and Cultural Psychology, Faculty of Psychology \& Educational Sciences, KU Leuven, Tiensestraat 102 B, 3000 Leuven, Belgium.

E-mail address: emanuele.politi@kuleuven.be (E. Politi).
} 
constraints and self-regulatory challenges in aligning their thoughts, feelings, and intentions with their actions (Sheeran \& Webb, 2016). To assess eventual boundary conditions of prosociality, in our research we moved beyond bonding prosocial intentions to also include bridging prosocial intentions and real-life bridging prosocial behaviors.

\subsection{Psychological underpinnings of prosociality}

Prosociality is deeply rooted in enduring attributes of the individual, such as personality traits, values, and beliefs (Caprara, Alessandri, \& Eisenberg, 2012; Penner, Fritzsche, Craiger, \& Freifeld, 1995). This altruistic motivation aroused by sympathetic and empathic concerns builds up around two organizing principles: First, prosociality requires people to think in collective rather than personal terms (Abele \& Wojciszke, 2007). Second, prosociality requires people to think in terms of cooperation rather than competition (Deutsch, 2006). When collective and cooperative motives are incorporated into a meaningful worldview, people should be the most sensitive to others' welfare, which is the ultimate foundation of altruism (Batson \& Powell, 2003). To test this general hypothesis, in our study we integrated three well-established research streams assessing individual differences in life principles and worldviews, namely basic individual values, ideological orientations, and core political values.

\subsubsection{Basic individual values}

Basic individual values serve as a coherent system of principles guiding individual everyday decision making, attitudes, and behaviors (Schwartz, 1992). Extensive research has shown that basic individual values coagulate personality traits into attitudinal preferences (e.g., Caprara, Schwartz, Capanna, Vecchione, \& Barbaranelli, 2006). Nineteen values have been consistently recognized across countries, and organized around four high-ordered factors: Conservation emphasizes order, self-restriction, preservation of the past, and resistance to change. Openness to change emphasizes independence of thought, action, and feelings and readiness for change. Self-enhancement emphasizes pursuit of self-interests and relative success and dominance over others. Selftranscendence emphasizes concern for the welfare and interests of others (for a more exhaustive overview, see Schwartz et al., 2012).

By combining collective and cooperative dispositions aimed at promoting redistribution among social groups, people valuing selftranscendence values (i.e., benevolence and universalism) should be the strongest proponent of prosociality. In line with previous research (Caprara et al., 2012; Schwartz, 2010), we therefore hypothesized a positive relation between self-transcendence values and prosociality (Hypothesis 1). Additionally, we expected the two components underlying self-transcendence values to show different relations to "bonding" and "bridging" types of prosociality (Schwartz, 2007). Benevolence inclines towards enhancing the welfare of people with whom one is in frequent personal contact, and should therefore be most strongly related to bonding prosociality (Hypothesis 1a). Universalism inclines towards enhancing the welfare of all humankind, and should therefore be most strongly related to "bridging" prosociality (Hypothesis $1 \mathrm{~b}$ ).

\subsubsection{Ideological orientations}

Two main perspectives have largely prevailed inquiries into prejudice and intergroup hostility, namely right-wing authoritarianism (RWA) and social dominance orientation (SDO). Numerous studies have shown that RWA and SDO correlates with attitudinal preferences (e.g., Duckitt \& Sibley, 2010; Sibley \& Duckitt, 2009). Although both RWA and SDO both exacerbate self-protective reactions, they convey generalized negativity against threatening others through different motivational mechanisms: Fueled by dangerous world beliefs, RWA draws boundaries to protect one's own community from symbolic threats, and relates to negative attitudes towards deviant outgroups seen as threatening social order, cohesion, and stability. Fueled by competitive world beliefs, SDO draws boundaries to protect dominant groups from realistic threats, and relates to negative attitudes towards subordinate outgroups seen as threatening status quo, hierarchy, and power. By combining collective and competitive dispositions aimed to oppose redistribution among social groups, people valuing SDO should be the strongest opponents of prosociality in favor of the welfare of others (Hypothesis 2). Because no research so far has analyzed the relation between ideological orientations and prosociality, we explore rather than predict the possible nuances between bonding and bridging prosociality.

\subsubsection{Core political values}

Prosociality is a form of civic participation in the public affairs pertaining to the community, and it is therefore likely to reflect specific political views prescribing how society should be organized. Accordingly, core political values are overarching normative principles and beliefs about government, citizenship, and society (Schwartz, Caprara, \& Vecchione, 2010). Two lay conceptions of citizenship seem to best organize core political values (Staerklé, 2015): The first is based on consensus in a community upon commonly agreed rules and moral conduct to ensure the groups' relative cohesiveness. This consensusbased lay conception of citizenship is based on moral, cultural and non-quantifiable attributes which define processes of recognition, and comprises core political values such as traditional morality, law and order, blind patriotism, and civil liberties. The second is based on the socio-economic position of groups in relation to other groups, recognizes structural and collective disadvantage, and grants legitimacy to social justice claims. This conflict-based lay conception of citizenship is based on material, tangible and quantifiable attributes which gives rise to processes of redistribution, and comprises core political values such as free enterprise, equality, and accepting immigrants. By combining collective and cooperative dispositions aimed to promote redistribution among social groups, people valuing equality and accepting immigrants should be the strongest proponent of prosociality in favor of the welfare of others (Hypothesis 3). Because no research so far has analyzed the relation between core political values and prosociality, we explore rather than predict the possible nuances between bonding and bridging prosociality.

\subsection{The present study}

We tested our set of hypotheses in a correlational study carried out in UK in the very midst of the COVID-19 outbreak, namely April 2020. At that time, UK was one of the European countries that were hit hardest by the virus. Moreover, the British government response lacked promptness and coordination in facing the first weeks of emergency (Yamey \& Wenham, 2020). These considerations made the investigation of prosociality among the British population ever timelier.

\section{Method}

\subsection{Participants and design}

British adults were invited to participate in an online study via the Prolific Academic website (https://prolific.ac). They completed measures assessing basic individual values, ideological beliefs, and core political values. Finally, participants reported their intentions to participate in a number of prosocial initiatives, and were asked to effectively perform two prosocial behaviors. The research protocol was approved by the Social and Societal Ethics Committee of KU Leuven. The total sample comprised 399 individuals with a mean age of 32 years $(S D$ $=11.32$ ), consisting of $27 \%$ men and $72 \%$ women. Controls comprised ethnic background, household income, subjective socio-economic status, and group-based relative deprivation. The exact wording of each item, additional information about psychometric characteristics of each measure assessed separately, all measures merged altogether in a unique measurement model, and complementary analyses can be found in the supplementary online material (SOM). Unless stated otherwise, main 
variables were measured on a 7-points scale, ranging from 1 (Strongly disagree) to 7 (Strongly agree) Measurement and structural equation models were performed using the R-package Lavaan (Rosseel, 2012).

\subsection{Main independent variables}

\subsubsection{Basic individual values}

We assessed Basic individual Values with 21 items derived from Schwartz et al. (2012). For each portrait, respondents indicated how similar the person was to themselves on a scale ranging from 1 (Not at all like me) to 6 (Very much like me). The 21 items respected the multidimensionality proposed by Schwartz et al. (2012). Five indicators measured the 5 values covering Self-Transcendence ( $\alpha=0.77)$, six items measured the 4 values covering Openness to Change ( $\alpha=0.80)$, six indicators measured the 4 values covering Self-Enhancement $(\alpha=0.82)$, and six indicators measured the 6 values covering Conservation $(\alpha=$ 0.75). Model fit was acceptable: $\chi^{2}(173)=392.50, p<.001$; CFI $=0.91$; $\mathrm{RMSA}=0.06,90 \%$ CI $[0.05 ; 0.06], p=.06$; SRMR $=0.06$.

\subsubsection{Right-wing authoritarianism}

We assessed Right-wing Authoritarianism (RWA) using 9 items derived from Duckitt, Bizumic, Krauss, and Heled (2010). Three indicators measured each underlying dimension: Authoritarian Submission $(\alpha=$ 0.88), Conventionalism ( $\alpha=0.77)$, and Authoritarian Aggression $(\alpha=$ 0.90 ). A hierarchical structure was modeled, whereby three indicators loaded each on a separate bonding latent factor, which in turn loaded on a second-order factor called RWA ( $\alpha=0.90)$. Model fit was good: $\chi^{2}(24)$ $=81.59, p<.001$; CFI $=0.97$; RMSA $=0.08,90 \%$ CI [0.06; 0.09], $p=$ $.005 ;$ SRMR $=0.06$.

\subsubsection{Social dominance orientation}

We assessed Social Dominance Orientation (SDO) using 4 items derived from (Ho et al., 2015). The internal reliability of the unidimensional scale was good ( $\alpha=0.85)$, and the model fit acceptable, $\chi^{2}(2)$ $=5.06, p=.002 ; \mathrm{CFI}=0.98 ; \mathrm{RMSA}=0.07,90 \% \mathrm{CI}[0.06 ; 0.09], p=.02$; $\mathrm{SRMR}=0.03$.

\subsubsection{Core political values}

We assessed Core Political Values with 21 items derived from (Schwartz et al., 2010). Three indicators measured each of the 7 underlying dimensions: Law and Order $(\alpha=0.83)$, Traditional Morality ( $\alpha$ $=0.85$ ), Equality $(\alpha=0.73)$, Free Enterprise $(\alpha=0.68)$, Civil Liberties ( $\alpha=0.74)$, Blind Patriotism ( $\alpha=0.82)$, and Accepting Immigrants $(\alpha=$ $0.86)$. Model fit was good: $\chi^{2}(168)=339.14, p<.001$; CFI $=0.94$; $\mathrm{RMSA}=0.05,90 \%$ CI $[0.04 ; 0.06], p=.43$; SRMR $=0.06$.

\subsection{Main dependent variables}

\subsubsection{Prosocial intentions}

We assessed prosocial intentions using 6 original items created for the purpose of the present research. Two indicators measured prosociality directed towards people physically and psychologically close to participants, and was named Bonding Prosocial Intentions, for example, "I am willing to do grocery shopping for those people in my neighborhood who are in need" $(r(398)=0.72, p<.001)$. Four indicators measured prosociality directed towards people physically and psychologically distant to participants, and was named Bridging Prosocial Intentions, for example, "I am willing to telework for the Department of International Development currently organizing a coordinated response to the corona pandemic in third-world countries" $(\alpha=0.84)$. Model fit was acceptable: $\chi^{2}(7)=32.55, p<.001 ;$ CFI $=0.97$; RMSA $=0.09,90 \%$ CI $[0.06 ; 0.12]$, $p=.004$; SRMR $=0.04$. When means for Bonding $(M=5.01, S D=1.65)$ and Bridging Prosocial Intentions $(M=4.36, S D=1.60)$ were compared, results showed that means differed, $t(398)=7.58, p<.001$.

\subsubsection{Prosocial behaviors}

After completing the self-report measures, participants performed two behaviors directly related to bridging prosociality. The first measure, Donation, consisted of donating (part of) the participation reward. Participants were asked to choose the amount to donate on a five-points scale. Of the whole sample, $42.9 \%$ did not donate to the charity organization; $22.6 \%$ donated $0.50 \mathrm{c} ; 17.8 \%$ donated $1.00 £ ; 2.5 \%$ donated $1.50 £ ; 14.3 \%$ donated $2.00 £$. The second measure, Petition, consisted of supporting an international solidarity campaign in response to COVID19. A general banner was followed by a number of claims made by the petition. Of the total sample, $52.6 \%$ signed the petition.

\section{Main results}

\subsection{Main correlates of prosocial intentions}

\subsubsection{Basic individual values}

Hypothesis 1 stated that Self-Transcendence should be a better predictor of prosocial intentions than other basic individual values. By examining the covariance matrix (see Table 1), Self-Transcendence and Openness to Change were both positively related to Bonding and Bridging Prosocial Intentions. This is not surprising, considering that they both express an anxiety-free growth, and are positively interrelated. In order to control for each other's effect, we included SelfTranscendence and Openness to Change in a single Structural Equation Model. ${ }^{1}$ Confirming Hypothesis 1 , Self-Transcendence was the only significant predictor of both Bonding, $\beta=0.38, z=4.94, p<.001$, and Bridging Prosocial Intentions $\beta=0.53, z=6.32, p<.001$. Conversely, when Self-Transcendence and socio-demographic variables were controlled for, the direct effect of Openness to Change was negligible for both Bonding, $\beta=-0.01, z=-0.15, p=.88$, and Bridging Prosocial Intentions, $\beta=-0.05, z=-0.76, p=.44$. By teasing apart the Benevolence and Universalism component of Self-Transcendence, results supported our predictions. Indeed, Benevolence, $\beta=0.22, z=2.29, p=$ .02 , and Universalism, $\beta=0.19, z=1.94, p=.05$, equally predicted Bonding Prosocial Intentions (Hypothesis 1a). No differences in effect sizes were observed, $\Delta \chi^{2}(1)=0.04, p=.83 ; \Delta \mathrm{CFI}=-0.001 ; \Delta \mathrm{BIC}=-$ 06. Conversely, Universalism, $\beta=0.42, z=4.18, p<.001$, and not Benevolence, $\beta=0.07, z=0.77, p=44$, predicted Bridging Prosocial Intentions (Hypothesis $1 \mathrm{~b}$ ).

\subsubsection{Ideological orientations}

Hypothesis 2 stated that SDO should be a better predictor of prosocial intentions than RWA. Results from the covariance matrix were in line with our predictions. Indeed, SDO was negatively related to both Bonding and Bridging Prosocial Intentions; RWA was instead negatively related to Bridging Prosocial Intentions only (Table 1). In order to estimate the unique contribution of each ideological orientation once controlling for the other, we included RWA and SDO in a single Structural Equation Model. Confirming Hypothesis 2, SDO was the only significant predictor of both Bonding, $\beta=-0.25, z=-2.55, p=.01$, and Bridging Prosocial Intentions $\beta=-0.32, z=-3.52, p<.001$. Conversely, when SDO and socio-demographic variables were controlled for, the direct effect of RWA was negligible for both Bonding, $\beta=0.15, z=1.45, p=.15$, and Bridging Prosocial Intentions, $\beta=-0.04$, $z=-0.43, p=.67$.

\subsubsection{Core political values}

Hypothesis 3 stated that Equality and Accepting Immigrants should be better predictors of prosocial intentions than the other core political values. Results from the covariance matrix were in line with our

\footnotetext{
${ }^{1}$ All Structural Equation Models reported henceforth included the following control variables: Age, gender, ethnic background, household income, subjective socio-economic status, and group-based relative deprivation.
} 
predictions. Equality and Accepting Immigrants were indeed positively related to both Bonding and Bridging Prosocial Intentions. Yet, when they were controlled for each other and socio-demographic variables in a single Structural Equation Model, Accepting Immigrants was weakly associated with Bonding, $\beta=0.13, z=1.81, p=.07$, and strongly associated with Bridging Prosocial Intentions, $\beta=0.30, z=3.42, p<$ .001. Similarly, Equality was unrelated to Bonding Prosocial Intentions, $\beta=0.07, z=1.02, p=.31$, and yet associated with Bridging Prosocial Intentions, $\beta=0.21, z=2.37, p=.02$.

\subsubsection{Basic individual values, ideological orientations and core political values}

As a final step, we included Self-Transcendence, SDO, Equality, and Accepting Immigrants in a unique SEM model. Results were robust and showed that Self-Transcendence explained unique variance of both Bonding, $\beta=0.38, z=3.96, p<.001$, and Bridging Prosocial Intentions, $\beta=0.37, z=4.03, p<.001$. Once Self-Transcendence and sociodemographic variables were controlled for, only Accepting Immigrants remained positively associated with Bridging Prosocial Intentions, $\beta=$ $0.17, z=2.02, p=.04$. Conversely, the effects of SDO and Equality on both Bonding and Bridging Prosocial Intentions canceled each other out and shrank to non-significance levels, all $p s>0.20$. An analysis of indirect effects revealed that the effect of SDO on Bonding Prosocial Intentions was fully captured by Self-Transcendence, $\beta=-0.20, z=$ $-3.56, p<.001$. Similarly, the effect of SDO on Bridging Prosocial Intentions was fully captured by Self-Transcendence, $\beta=-0.20, z=$ $-3.80, p<.001$, and Accepting Immigrants, $\beta=-0.12$, $z=-1.97, p=$ .05 .

\subsection{Main correlates of prosocial behaviors}

We replicated the same analytical procedure and regressed SelfTranscendence, SDO, Equality, and Accepting Immigrants on Donation and Petition respectively. Whereas Donation was measured on a continuous scale, Petition was dichotomous. Therefore, multiple regression and binary logistic regression models with control variables were performed on the two prosocial behaviors. Results were robust and confirmed the same patterns observed for Bridging Prosocial Intentions. When basic individual values, ideological orientations, and core political values were entered separately, Self-Transcendence, SDO, Equality and Accepting Immigrants predicted Donation and Petition. Moreover, when all the significant predictors were entered jointly, SelfTranscendence was the unique predictor of Donation (Table 2). A test for indirect effects revealed that the effect of SDO on Donation was partially captured by Self-Transcendence, $\beta=-0.04,95 \%$ CI $[-0.08$, $-0.01]$. Regarding Petition, results showed that Self-Transcendence and Equality both increased the probability of signing the petition. Moreover, the effect of SDO on Petition was fully captured by SelfTranscendence, $b_{\ell}=-0.05,95 \%$ CI $[-0.12,-0.01]$, and Equality, $b_{\ell}$ $=-0.17,95 \% \mathrm{CI}[-0.32,-0.06]$.

Table 2

Predictors of prosocial behaviors.

\begin{tabular}{|c|c|c|c|c|}
\hline & \multicolumn{2}{|c|}{$\begin{array}{l}\mathrm{R}^{2}=0.19 \\
\text { Donation }\end{array}$} & \multicolumn{2}{|c|}{$\begin{array}{l}\mathrm{R}^{2} \text { Naglelkerke }=0.22 \\
\text { Petition }\end{array}$} \\
\hline & $\beta$ & $t$ & $b_{\exp }$ & Wald \\
\hline SDO & -0.02 & $-0.19^{\text {N.S. }}$ & 0.90 & $0.76^{\text {N.S. }}$ \\
\hline Self-Transcendence & 0.38 & $3.96 * * *$ & 1.60 & $7.32^{* *}$ \\
\hline Equality & -0.15 & $-1.28^{\mathrm{N} . \mathrm{S}}$ & 1.53 & $9.35^{* *}$ \\
\hline Accepting Immigrants & 0.08 & $0.90^{\text {N.S. }}$ & 1.16 & $1.97^{\text {N.S. }}$ \\
\hline
\end{tabular}

Note: The total variance explained is reported on the top of the table. Whereas estimates for donation were extracted from a multiple regression model, estimates for petition were extracted from a binary logistic regression model, and expressed in odds ratio $\left(b_{\text {exp }}\right.$ ) Controls: Age, gender, ethnic background, household income, subjective socio-economic status, and group-based relative deprivation. N.S. $p>.10, \dagger p \leq .10,{ }^{*} p \leq .05,{ }^{* *} p \leq .01,{ }^{* * *} p \leq .001$. 


\section{Discussion}

This research was the first attempt to articulate basic individual values, ideological orientations, and core political values in an integrative model to predict both bonding and bridging forms of prosociality in the midst of the COVID-19 outbreak. Overall, prosociality was tied up with altruistic motivations to care about the welfare of others. Although this claim might seem straightforward, others have claimed that prosociality is not only driven by altruistic motives, but also by self-vested interest, attraction, and self-presentational goals (Batson \& Powell, 2003; Stürmer, Snyder, \& Omoto, 2005). What is more, participants were more inclined to support face-to-face networks within their own community (i.e., bonding prosocial intentions) than vulnerable populations across group boundaries (i.e., bridging prosocial intentions). Of importance, when individual orientations combined collective and cooperative motives in a meaningful worldview, participants showed stronger bridging prosocial intentions and behaviors alike (Wolf, Haddock, Manstead, \& Maio, 2020). Indeed, universal values, as well as political beliefs built up on egalitarian principles and acceptance of immigrants, were all positively related to bridging prosociality. Conversely, competitive orientations towards intergroup relations, as captured by SDO, were negatively related to both bonding and bridging prosociality, thereby pinpointing the pernicious effects of SDO on community resilience and social cohesion. Because core political values were only frailly associated with bonding types of prosociality, more research is needed to identify political principles associated with community resilience and social cohesion.

As this study was merely correlational, we did not formulate any causal hypothesis. Yet, in our data ideological orientations preceded basic individual values in an alleged causal chain. Indeed, selftranscendence fully mediated the effect of SDO, and was therefore the most proximal predictor of both bonding and bridging forms of prosociality. This finding seems to diverge from previous research, whereby basic values and worldviews were considered the motivational foundation of ideological orientations (Cohrs, Moschner, Macs, \& Kielmann, 2005; Sibley \& Duckitt, 2009). Experimental studies are needed to tease apart the causal relation between basic individual values, ideological orientations, and core political values in explaining prosociality.

Our research suggested that collective and cooperative orientations are the main motivational underpinnings supporting prosociality. Yet, alternative life goals and worldviews might sustain prosociality under specific conditions (Bekkers \& Wiepking, 2011; Halabi \& Nadler, 2017). Our research should be therefore extended with interventions inducing social norms and distinct mindsets to spur prosociality among a larger share of people. For instance, achievement is particularly associated with the pursuit of social approval, and might elicit prosociality when public acclaim is at stake. Power values emphasize competitive advantage over others, and might elicit prosociality when others' dependency is preserved. Conformity and security values urge people to maintain order, and might elicit prosociality when acting in favor of others is a matter of public health and safety. Self-direction and stimulation values incite people to acquire new skills and try new experiences, and might elicit prosociality in situations where acting in favor of others brings about self-fulfillment.

Future research should also try to reduce the gap between intentions and behaviors among people who are already intended to support others. Induced hypocrisy, a two-step procedure in which individuals publicly advocate a desirable behavior and then privately reflect on their own failures to implement this very behavior (Aronson, Fried, \& Stone, 1991; Priolo et al., 2019), seems particularly appropriate to this scope. Although never used in the realm of prosociality, this dissonance-based persuasion technique aims at raising awareness of the lack of consistency between cherished personal attitudes and actual behavior. When induced among people valuing self-transcendence, hypocrisy may entail feelings of guilt, thereby promoting concrete prosocial behaviors (Basil, Ridgway, \& Basil, 2006; Carlsmith \& Gross, 1969).

\section{Conclusion}

Natural calamities may be extremely stressful for individuals and whole societies. Yet, if accompanied with effective coping resources, threats are transformed into occasions to grow personally and collectively (Benight \& Bandura, 2004; Wlodarczyk, Basabe, Páez, Villagrán, \& Reyes, 2017). Prosociality is a key factor promoting community resilience and growth (Drury, 2012; Solnit, 2009). By helping and supporting others in need, not only do people fulfill their altruistic motivations, they also establish a virtuous circle from which they themselves may benefit in the first place. Research is urgently needed to understand the psychological mechanisms promoting and sustaining prosociality in response to the COVID-19 outbreak (Elcheroth \& Drury, 2020; Jetten, Reicher, Haslam, \& Cruwys, 2020). The increased physical distancing that has been imposed upon people to limit the spreading of COVID-19 needs indeed to be accompanied by sustained efforts to bring people together, because "no man is an island entire of itself; every man is a piece of the continent, a part of the main" (Donne, 1627).

\section{CRediT authorship contribution statement}

Emanuele Politi: Conceptualization, Methodology, Formal analysis, Writing - original draft. Jasper Van Assche: Conceptualization, Software, Investigation, Writing - review \& editing. Gian Vittorio Caprara: Writing - review \& editing, Validation. Karen Phalet: Writing - review $\&$ editing, Validation, Supervision.

\section{Acknowledgements}

This research was supported by an Early Postdoctoral Mobility grant from the Swiss National Foundation for Scientific Research awarded to Emanuele Politi (P2LAP1_L877Og).

\section{Appendix A. Supplementary Online Material}

Supplementary analyses, datascript and database to this article can be found online at https://doi.org/10.1016/j.paid.2020.110534.

\section{References}

Abele, A. E., \& Wojciszke, B. (2007). Agency and communion from the perspective of self versus others. Journal of Personality and Social Psychology, 93, 751-763. https://doi. org/10.1037/0022-3514.93.5.751.

Andrighetto, L., Vezzali, L., Bergamini, G., Nadi, C., \& Giovannini, D. (2016). Inside the earthquake: Perceived disaster exposure and helping intentions among Italian and immigrant victims of the 2012 Italian earthquakes. Group Processes \& Intergroup Relations, 19, 753-768. https://doi.org/10.1177/1368430215591040.

Aronson, E., Fried, C., \& Stone, J. (1991). Overcoming denial and increasing the intention to use condoms through the induction of hypocrisy. American Journal of Public Health, 81, 1636-1638. https://doi.org/10.2105/AJPH.81.12.1636.

Baron, J., \& Szymanska, E. (2011). Heuristics and biases in charity. In D. M. Oppenheimer, \& C. Y. Olivola (Eds.), The science of giving (pp. 215-235). Psychology Press.

Basil, D. Z., Ridgway, N. M., \& Basil, M. D. (2006). Guild appeals: The mediating effect of responsibility. Psychology \& Marketing, 23, 1035-1054. https://doi.org/10.1002/ mar. 20145.

Batson, C. D. (1991). The altruism question: Toward a social psychological answer. Erlbaum.

Batson, C. D., \& Powell, A. A. (2003). Altruism and prosocial behavior. In Theodore Millon, \& Melvin Lerner, J (Eds.), Handbook of psychology (Vol. 5): Personality and social psychology (pp. 463-484). Wiley.

Bekkers, R., \& Wiepking, P. (2011). A Literature Review of Empirical Studies of Philanthropy: Eight Mechanisms That Drive Charitable Giving. Nonprofit and Voluntary Sector Quarterly, 40, 924-973. https://doi.org/10.1177/ 0899764010380927.

Benight, C. C., \& Bandura, A. (2004). Social cognitive theory of posttraumatic recovery: The role of perceived self-efficacy. Behaviour Research and Therapy, 42, 1129-1148. https://doi.org/10.1016/j.brat.2003.08.008.

Caprara, G. V., Alessandri, G., \& Eisenberg, N. (2012). Prosociality: The contribution of traits, values, and self-efficacy beliefs. Journal of Personality and Social Psychology, 102, 1289-1303. https://doi.org/10.1037/a0025626.

Caprara, G. V., Schwartz, S., Capanna, C., Vecchione, M., \& Barbaranelli, C. (2006). Personality and politics: Values, traits, and political choice. Political Psychology, 27, 1-28. https://doi.org/10.1111/j.1467-9221.2006.00447.x. 
Caprara, G. V., Steca, P., Zelli, A., \& Capanna, C. (2005). A new scale for measuring adults' prosocialness. European Journal of Psychological Assessment, 21, 77-89. https://doi.org/10.1027/1015-5759.21.2.77.

Carlsmith, J. M., \& Gross, A. E. (1969). Some effects of guilt on compliance. Journal of Personality and Social Psychology, 3, 232-239. https://doi.org/10.1037/h0027039.

Cohrs, J. C., Moschner, B., Macs, J., \& Kielmann, S. (2005). The motivational bases of right-wing authoritarianism and social dominance orientation: Relations to values and attitudes in the aftermath of September 11, 2001. Personality and Social Psychology Bulletin, 31, 1425-1434. https://doi.org/10.1177/0146167205275614.

Deutsch, M. (2006). Cooperation and competition. In M. Deutsch, P. T. Coleman, \& E. C. Marcus (Eds.), The handbook of conflict resolution: Theory and practice (pp. 23-42). Jossey-Bass.

Donne, J. (1627). Meditation XVII. In J. Donne, \& A. Raspa (Eds.), Devotions upon emergent occasions. Oxford University Press.

Drury, J. (2012). Collective resilience in mass emergencies and disasters. In J. Jetten, C. Haslam, \& S. A. Haslam (Eds.), The social cure: Identity, health and well-being (pp. 195-215). Psychology Press.

Duckitt, J., Bizumic, B., Krauss, S. W., \& Heled, E. (2010). A tripartite approach to rightwing authoritarianism: The authoritarianism-conservatism-traditionalism model. Political Psychology, 31, 685-715. https://doi.org/10.1111/j.14679221.2010.00781.x.

Duckitt, J., \& Sibley, C. G. (2010). Personality, ideology, prejudice, and politics: A dualprocess motivational model. Journal of Personality, 78, 1861-1894. https://doi.org/ 10.1111/j.1467-6494.2010.00672.x.

Elcheroth, G., \& Drury, J. (2020). Collective resilience in times of crisis: Lessons from the literature for socially effective responses to the pandemic. The British Journal of Social Psychology, 59, 703-713. https://doi.org/10.1111/bjso.12403 (e12403).

Graziano, W. G., Habashi, M. M., Sheese, B. E., \& Tobin, R. M. (2007). Agreeableness, empathy, and helping: A person $\times$ situation perspective. Journal of Personality and Social Psychology, 93, 583-599. https://doi.org/10.1037/0022-3514.93.4.583.

Halabi, S., \& Nadler, A. (2017). The intergroup helping as status relations (IHSR) model: Giving, seeking and receiving help as tools to maintain or challenge social inequality. In E. Van Leewen, \& H. Zagefka (Eds.), Intergroup helping (pp. 205-221). Springer.

Ho, A. K., Sidanius, J., Kteily, N., Sheehy-Skeffington, J., Pratto, F., Henkel, K. E., ... Stewart, A. L. (2015). The nature of social dominance orientation: Theorizing and measuring preferences for intergroup inequality using the new SDO7 scale. Journal of Personality and Social Psychology, 109, 1003-1028. https://doi.org/10.1037/ pspi0000033.

Jetten, J., Reicher, S. D., Haslam, S. A., \& Cruwys, T. (2020). Together apart: The psychology of Covid-19. Sage.

Patulny, R. V., \& Lind Haase Svendsen, G. (2007). Exploring the social capital grid: Bonding, bridging, qualitative, quantitative. International Journal of Sociology and Social Policy, 27, 32-51. https://doi.org/10.1108/01443330710722742.
Penner, L. A., Fritzsche, B. A., Craiger, J. P., \& Freifeld, T. R. (1995). Measuring the prosocial personality. In J. Butcher, \& C. Spielberger (Eds.), Advances in personality assessment (pp. 147-163). Lawrence Erlbaum Associates.

Priolo, D., Pelt, A., Bauzel, R. S., Rubens, L., Voisin, D., \& Fointiat, V. (2019). Three decades of research on induced hypocrisy: A meta-analysis. Personality and Social Psychology Bulletin, 45, 1681-1701. https://doi.org/10.1177/0146167219841621.

Rosseel, Yves (2012). Lavaan: An R package for structural equation. Journal of Statistical Software, 48, 1-36. https://doi.org/10.18637/jss.v048.i02.

Schwartz, S. H. (1992). Universals in the content and structure of values: Theoretical advances and empirical tests in 20 countries. In M. P. Zanna (Ed.), Advances in experimental social psychology (pp. 1-65). Academic Press.

Schwartz, S. H. (2007). Universalism values and the inclusiveness of our moral universe. Journal of Cross-Cultural Psychology, 38, 711-728. https://doi.org/10.1177/ 0022022107308992.

Schwartz, S. H. (2010). Basic values: How they motivate and inhibit prosocial behavior. In M. Mikulincer, \& P. R. Shaver (Eds.), Prosocial motives, emotions, and behavior: The better angels of our nature. (pp. 221-241). American Psychological Association Press.

Schwartz, S. H., Caprara, G. V., \& Vecchione, M. (2010). Basic personal values, core political values, and voting: A longitudinal analysis. Political Psychology, 31, 421-452. https://doi.org/10.1111/j.1467-9221.2010.00764.x.

Schwartz, S. H., Cieciuch, J., Vecchione, M., Davidov, E., Fischer, R., Beierlein, C., ... Konty, M. (2012). Refining the theory of basic individual values. Journal of Personality and Social Psychology, 103, 663-688. https://doi.org/10.1037/a0029393.

Sheeran, P., \& Webb, T. L. (2016). The intention - Behavior gap. Social and Personality Psychology Compass, 10, 503-518. https://doi.org/10.1111/spc3.12265.

Sibley, C., \& Duckitt, J. (2009). Big-five personality, social worldviews, and ideological attitudes: Further tests of a dual process cognitive-motivational model. Journal of Social Psychology, 149, 545-561. https://doi.org/10.1080/00224540903232308.

Solnit, R. (2009). A paradise built in hell: The extraordinary communities that arise in disaster. Viking.

Staerklé, C. (2015). Social order and political legitimacy. In G. Sammut, E. Andreouli, G. Gaskell, \& J. Valsiner (Eds.), The Cambridge handbook of social representations (pp. 280-294). Cambridge University Press.

Stürmer, S., Snyder, M., \& Omoto, A. M. (2005). Prosocial emotions and helping: The moderating role of group membership. Journal of Personality and Social Psychology, 88, 532-546. https://doi.org/10.1037/0022-3514.88.3.532.

Wlodarczyk, A., Basabe, N., Páez, D., Villagrán, L., \& Reyes, C. (2017). Individual and collective posttraumatic growth in victims of natural disasters: A multidimensional perspective. Journal of Loss and Trauma, 22, 371-384. https://doi.org/10.1080/ 15325024.2017.1297657.

Wolf, L. J., Haddock, G., Manstead, A. S. R., \& Maio, G. R. (2020). The importance of (shared) human values for containing the COVID-19 pandemic. The British Journal of Social Psychology., 59, 618-627. https://doi.org/10.1111/bjso.12401.

Yamey, G., \& Wenham, C. (2020, July). The U.S. and U.K. were the two best prepared nations to tackle a pandemic - What went wrong? Time. Retrieved from https://time.co $\mathrm{m} / 5861697 /$ us-uk-failed-coronavirus-response/. 